\title{
Maintaining Building Function During a Fire Event: Analysis of Hospital Fire and Smoke Control Systems
}

\author{
Daniel Fleck, P.E. and Scott W. Kramer, Ph.D. \\ McWhorter School of Building Science, 118 M. Miller Gorrie Center, Auburn University, AL 36849, USA
}

\begin{abstract}
Fires in a critical facility such as a hospital could lead to catastrophic outcomes if the fire and smoke control systems are not properly installed, monitored, and maintained. This research studied a single facility and its smoke management system, primarily focusing on the HVAC system and how it responds in the event of a fire. Key facilities management staff were interviewed and national life safety codes were reviewed. The research indicated that each facility is going to operate completely different due to the differing needs; however, care must always be taken to properly locate functional hospital units in corresponding smoke zones to minimize the loss of a functional healthcare system after a fire event. Additionally, the need to digitize and centrally monitor all aspects of the smoke and fire control system is clearly evident, as this will provide a system that can be repaired quickly and efficiently.
\end{abstract}

(C) 2018 The Authors. Published by Diamond Congress Ltd., Budapest University of Technology and Economics Peer-review under responsibility of the scientific committee of the Creative Construction Conference 2018.

Keywords: smoke, fire, control, HVAC, zone, damper, sprinkler, atrium;

\section{Introduction}

Have you ever wondered what would happen if a hospital caught on fire? Would they have to evacuate everyone? Would they be able to triage the people injured by the fire? Generally speaking, hospitals are set up to contain smoke and fire to an area designated by certain building codes and design layout. There are active features, such as automatic sprinklers, mechanical systems, and smoke evacuation fans and there are passive features like fire and smoke dampers and physical barriers. The combination of these features provides assistance to contain and control a fire to a certain area. The ability to control fire and smoke is extremely important, as it is an essential function in order to protect occupants in a building. These items are not in place to protect the contents of the facility, as much as they are there to protect the people who may not be able to evacuate without a great deal of assistance, and the staff that care for them.

This research discusses the intent and design of a key piece of this entire system, the Heating Ventilation and Air Conditioning (HVAC), and looks toward the future and how these systems can be improved upon. This is especially important to hospitals that are undergoing massive construction and remodelling projects to maintain a facility that is able to provide efficient and effective patient care.

\section{Literature Review}

In reviewing previous research literature for this topic, a significant amount of research was completed in the 1980's; however, it seemed to taper off until the 2000's. The most largely researched topic in this field is fire and smoke 
dampers. Fire dampers are rarely activated, as they are required to get to a high heat prior to activating. Smoke dampers may activate once the system senses smoke.(Felker, 2008) These systems can be very simple in design where the entire supply side of the system shuts down once smoke is detected, or amazingly complex where many systems are intertwined with each other like dampers, logic-based HVAC, automatic sprinklers, mass notification system, fire alarm, and building automation. (Banse, 2006). The HVAC systems don't seem to be studied much as they are generally programmable and will vary from facility to facility.

Additionally, there are multiple national code manuals that have extensive information and guidance on how these systems are designed, installed, and maintained. The National Fire Protection Association (NFPA) is one of the leading organizations that provide guidance on fire, electrical, and hazard related items. NFPA 101 Life Safety Code discusses topics such as requirements for new and existing health care facilities. This code manual discusses fire and smoke rated walls, fire stopping, automatic door releases, dampers, and many other items involved in the life safety of a health care facility. It also discusses other types of facilities, but health care facilities are the primary focus of this paper. ("NFPA 101: Life Safety Code $\left.{ }^{\circledR}, " 2015\right)$ NFPA 99 Health Care Facilities Code establishes risk and facility requirements based on this risk to patients, staff, and visitors to health care facilities.("NFPA 99: Health Care Facilities Code," 2015) Finally, NFPA 92 Standard for Smoke Control Systems details how there are two (2) different types of systems: dedicated and non-dedicated. The dedicated systems have equipment installed for the single purpose of providing smoke control. Non-dedicated systems change the normal equipment to provide this service in the event of smoke detection.

\section{Background}

As hospitals continue to grow, the need for proper space planning and facility management grows with it. For example, an area that was built thirty years ago for a specific use may no longer be the same as it was when the space was built. Areas that were once in-patient wards are now out-patient clinics or community living centers, cafeterias have become more streamlined, and open space for family and patients to wait for their appointments has increased. Additionally, pharmacy needs have grown, emergency care needs have changed, and specialty equipment has improved significantly over the years. These are only just a few of the changes that have occurred over the years. Each time a hospital's needs change - they cannot tear down the building and start over again. They must remodel the space.

All of these changes require changes to the way the facility is managed and how the space is planned. In the event of a fire, many things need to function in a proper sequence to consider the control of a fire to be successful. Magnetic door holds may need to release, HVAC systems may need to change or stop flow. Automatic sprinklers may need to release. The mass notification systems required to alert the area and emergency lighting needs to be properly light the exit paths for the area.

In a hospital, the HVAC system is one of the largest and most important components of this entire facility. It is responsible for maintaining temperature and humidity, as well as replacing the building air with fresh outside air. Also, there are strict requirements for how many times the air in a certain space is replaced.("EC.02.05.01 - Clinical Impact | Joint Commission," n.d.) This helps with infection control in an area where patients are especially vulnerable due to weakened immune systems. Finally, the HVAC system is one of the primary responders in the event of a fire, with the ability to remove smoke from an area, starve the fire for oxygen or provide a smoke free pathway to safety. If properly equipped, the system will be able to contain the fire event, with the aid of automatic sprinklers, to a designed smoke control zone. This containment should be capable of maintaining this space for a designed amount of time until the first responders arrive on site.

\section{Purpose of Study and Research Objective}

Engineered fire control is a vast expanse of mechanical and electrical systems that all tie together: this study will focus mainly on the heating ventilation and air conditioning (HVAC) systems and the associated controls around its function during a fire event. Since it is tied to many other systems, if the system doesn't properly function, other systems risk becoming less effective.

The objective of this study is to increase awareness of the importance of these systems and their maintenance as well as requirements for upgrading the systems when necessary. Hospitals throughout the world may have the capabilities 
to perform a mass evacuation of the entire hospital, but this always a last option. If a mass evacuation was required, one may consider the following:

1. Where would the patients go?

2. What happens if they are connected to life support or oxygen? How long do mobile devices sustain this need?

3. Are there enough staff in a hospital to perform this type of evacuation?

In the event of a fire, the hospital would much rather evacuate a specific area of the hospital while the other areas are able to maintain function as normal. The other areas can take on the patients of the evacuated area, but the displaced patients are at much less risk than being completely evacuated from the facility with the need to be relocated to another hospital in the local vicinity.

For the purpose of this study - a specific facility is going to be detailed as the author has the ability to access the entire facility and staff for research purposes. The facility will not be named for public safety reasons, due to the risk that some of the details in this writing could be used improperly. This hospital has over 4000 rooms with a combined usage space of over 1.5 million square feet. The facility has fully functioning emergency department, community living center, outpatient clinics, 20+ operating rooms, and ambulatory care units. There are over 2700 staff on site on a normal workday and approximately 200 patients that do not leave the facility at the end of the day. The number of people that visit the facility (including family members and patients there for a regular appointment and will leave before the end of the day) is not monitored. The building construction was completed in the late 1980's for approximately $\$ 200$ million. Over the years, the facility needs have evolved since the new facility was opened. With the changing needs, there is a greater need for larger and more complex construction projects. These projects change areas significantly; therefore, life safety designers are responsible for ensuring that the proposed renovations will allow the facility to meet its requirements.

\section{Rational for the Study}

Generally, causalities in hospital fires are low, compared to other building structures. This is due to the increased requirements for proper design and control of the systems that can aid in the containment of a fire event. However, the need still exists. From 2012 to 2014 there were over 1,100 fire in hospitals in the United States, and approximately $27 \%$ of these fires were non-confined fires, meaning that they were larger structure fires.("Hospital Fires (2012-2014)," n.d.)

These relatively small number could easily become catastrophic if the engineered fire and smoke systems that are in place were not there, or if they were to fail. In the early and mid-1900's it was not uncommon for there to be many deaths in hospital fires. 129 people died in the Cleveland Clinic in 1929, 16 people died in the 1961 Hartford Fire in Connecticut. Even in more recent past there have been deaths in hospital fires including 6 in Virginia in 1994 and 3 in New York in 1993. (Ahrens, 2012)

\section{Loss Measures for Hospitals and All Other Medical} Facility Fires (Three-Year Average, 2012-2014)

\begin{tabular}{lcc}
\hline \multicolumn{1}{c}{ Loss Measure } & Hospital Fires & $\begin{array}{c}\text { All Other } \\
\text { Medical Facility Fires }\end{array}$ \\
\hline Average Loss: & & \\
\hline Fatalities/1,000 Fires & 0.4 & 0.6 \\
\hline Injuries/1,000 Fires & 17.3 & 19.6 \\
\hline Dollar Loss/Fire & $\$ 6,030$ & $\$ 11,290$ \\
\hline Source: National Fire Incident Reporting System (NFIRS) 5.0. &
\end{tabular}

Figure 1 - Loss Measure for Hospitals and All Other Medical Facility Fires. (“Hospital Fires (2012-2014),” n.d.)

Looking at Figure 1 above, hospitals have generally been a safe place to be in the event of a fire, but there is still room for improvement. Additionally, while the numbers may be low, a value that is not reported here would be the amount of time lost to cleaning and repairing the area that was affected by the fire. If an area that generally houses 20-30 overnight patients, those patients will need to be relocated and the area is required to undergo full inspection 
and cleaning. Most wards in the studied facility are approximately $12,000 \mathrm{SF}$, which is contained in a single smoke control zone. This entire area would be closed until a full-scale remediation and investigation was completed.

While it appears that hospitals have control of their ability to control smoke and fire, the ever-moving target for efficient and effective patient care has caused these facilities to undergo massive remodelling and construction projects that change the overall layout of the originally designed space. If fire and smoke control is not given high priority during these designs, a major flaw is lingering in the background that can create critical and life-threatening outcomes. The need to verify that the facility is maintaining the most efficient and effective manners of smoke and fire control is critical due to these changes.

\section{Research Design}

In order to best understand the facility that is under review, plus understand the national design requirements, this study will use a qualitative research design. Research papers and national codes and standards will be reviewed and then the facility under the study will be analyzed and interviews will be performed with staff that is intimate with the system. A comparison of the research will be completed which will provide a conclusion of how the facility should be maintaining and upgrading its system as it moves forward into the future. The interviews will cover three separate groups of hospital staff:

1. HVAC Facilities Engineering Staff ( 2 employees)

a. This is the staff that maintains the air-handling units as well as monitors the fire and smoke dampers. Since the sprinkler lines are monitored for flow and tied to the HVAC system, this staff also monitors these items.

2. ATS Facilities Engineering Staff (1 employee)

a. This is the staff that maintains all of the building automation systems including, fire alarms, smoke detectors, automatic and magnetically held doors, and the mass notification system.

3. Safety and Emergency Management Staff ( 2 employees)

a. This is the staff that maintains the evacuation plans as well as upgrading and testing policy and procedures. They develop standard operating procedures for the facility and have the knowledge of how the facility as a whole is designed to respond to a fire event. They also compile data required to be submitted to various local, state, and federal agencies during an inspection.

While the sample set is small, this interview will cover over 85 years of expertise and some of these staff have been with this specific facility since the early stages of this building being operated. They have witnessed the changes and upgrades over the years and have the most specific knowledge of the systems strengths and weaknesses. The 10 interview questions will remain the same across all of the interviewees, as each will provide their knowledge of that item. Additionally, the questions asked are intended to open to floor for further discussion into the depth of the interviewees knowledge. A set of the interview questions can be found below. This information will be combined to develop the integrated answer of how the facility operates through a multitude of connected systems. This also shows how complex these designs can become and how the need for clear and concise communication is key in a facility of this size.

\section{Data Collection and Analysis}

The primary sources of data come from National Organizations - such as the NFPA and Joint Commission and personal interviews from staff members. The collection of data from the code books provided a detailed understanding of the requirements that the facility need to meet and how they need to operate. They guided the development of the interview questions that were presented to the interviewed staff. The questions were simple - but opened the table for discussion to get further into the details of the overall operation of the facility. 
The interview questions are detailed below

1. How do you control your fire and smoke dampers?

a. Do you have a firefighter control panel?

b. If yes, how often is the system tested?

2. Does the facility have a fully engineered smoke control system?

a. How much has the system changed since the building opened approximately 30 years ago?

3. What systems are tied to the HVAC system?

a. What happens to the HVAC system when a smoke alarm goes off?

b. What happens to the HVAC system when a hand-pull alarm goes off?

c. What happens to the HVAC system when the sprinkler system goes off?

d. What releases the magnetic door hold opens to seal a smoke zone?

4. What would happen if the fire left one zone and tripped an alarm in another zone?

a. Does the system recognize the need for a mass evacuation?

5. This facility has 3 large atria within the building - how do you manage a smoke or fire event in these areas?

6. Can you provide any information or feedback of fire/evacuation events in the facility?

7. Research shows that kitchen fires are leading cause of fires.

a. What type of fire suppression system is in the kitchen in this facility?

b. Does the kitchen share a HVAC system with any patient care areas?

8. What is unique about this facility and how it responds to a fire/smoke event?

The other two interview questions helped detail the level of experience the interviewee had with this (and other) facilities and the ability to release the information provided in the interview.

Interviews were performed on five (5) separate staff members - each with a different work requirement at the hospital. This allows the data received to have a different, but still correct, answer as each person has varying responsibilities regarding the fire safety and smoke management system.

\section{Interview Panel}

- $\quad$ Donald C - shop supervisor - 12 years' experience -6 at this facility

- Donald $\mathrm{S}$ - shop technician - 35 years' experience -35 at this facility

- Kristian $\mathrm{V}$ - shop supervisor -7 years' experience -6 at this facility

- Pamela $\mathrm{R}-$ administrative manager -25 years' experience -15 at this facility

- John $\mathrm{E}$ - administrative employee -11 years' experience -1 at this facility

\section{Facility HVAC Fire Response}

The HVAC system only responds to a fire within the facility when the sprinkler system is activated and the flow switch senses that water is flowing into that zone. This limited response minimizes false alarms to the HVAC system and only requires the change of the system in the most extreme of events. The interviewees state that the smoke alarms trip semi-frequently for things like - burnt toast or popcorn, stubborn patients who smoke in their room, and other minor things that do not warrant a massive change to the system. The smoke sensors are ceiling mounted in all areas of the hospital and are also mounted in the supply and return ducts of the HVAC system. While these sensors may still trigger an audible and visual alarm for the area to be evacuated, they will not warrant a change in the HVAC system. However, the magnetic door releases are tripped in the event of any of these events setting off the alarm. This is due to the simplification of the alarm system and the ease of resetting the doors by just opening them once the alarm is turned off. This also keeps the general public from wandering into the space, regardless of what tripped the alarm. These sensors also report to a central monitoring station monitored by staff that have the ability to respond quickly to verify the magnitude of the response necessary. If the fire department responds to a fire in the facility, there are read-only firefighter panels at all of the main entrances to the hospital. This will provide critical information to the response team when entering the facility, but does not give the responders the ability to control the airflow or sprinklers in the area that is under alarm. (V, Kristian, 2017)

The facility has 87 smoke zones and each one responds depending on its location in proximity to a smoke event. If it is directly adjacent to the area, and on the same floor, the area that is containing the smoke will go into negative pressure and $100 \%$ exhaust to outside as to not recycle any of the contaminated air to adjacent areas that share the same air handler. This will 'sandwich' the smoke area with positive pressure while maintaining the negative pressure in the affected area. This is accomplished with smoke dampers that are placed within the ducts of the system. The 
smoke dampers in this facility are not digital and do not report back anywhere to detail their status of open/close. (V, Kristian, 2017)

\section{Scenario 1: Burnt toast in break room of patient care ward}

Smoke detector senses smoke and sets off audible and visual alarm in the ward. Hospital wide announcement for a "Code Red" in specified ward. Safety team and police respond to alarm and determine to cancel the automatic call for the fire department. The alarm is cancelled. Since the HVAC system never changed operation, the smell of burnt toast may spread throughout the ward and could possibly make it to adjacent wards that share the same HVAC system.

\section{Scenario 2: Linen fire in laundry area}

Smoke detector senses smoke and sets off audible and visual alarm. Hospital wide announcement for a "Code Red" in specified area. Prior to safety team and police response, fire reaches $\sim 165^{\circ} \mathrm{F}$ and fire sprinkler releases. At this point, the flow switch in the sprinkler system senses flow and the HVAC system serving this area closes the smoke damper and stops the ability for the system to recycle smoke-filled air back from this area back into the system. This area goes into negative pressure by stopping the flow of supply air into the space. Adjacent areas on the same floor will go into positive pressure by reducing the flow of return air from the space. This positive/negative system helps contain the smoke to a specific area. Fire department responds to fire. Once the system can return to normal, the smoke dampers need to be manually reset by the facility staff.

\section{Scenario 3: Deliberate fire in the atrium}

Smoke detector senses smoke and sets off audible and visual alarm. Hospital wide announcement for a "Code Red" in specified area. Prior to safety team and police response, fire reaches $\sim 165^{\circ} \mathrm{F}$ and fire sprinkler releases. At this point, the flow switch in the sprinkler system senses flow and the HVAC system serving this area closes the smoke damper and stops the ability for the system to recycle smoke-filled air back from this area back into the system. This area goes into negative pressure and it also releases 4 spring-loaded trap doors at the top of the atrium to push all of the smoke out of the atrium. There are 23 separate zones that are adjacent to the largest atrium that will have to adjust their flow to maintain a positive pressure in their area. Fire department responds to fire. Once the system can return to normal the smoke dampers need to be manually reset by the facility staff.

There are 87 different scenarios in this facility - one for each zone.

When a fire occurs, all other requirements are ignored - temperature, humidity, required airflow, etc. The priority for the facility is that the event is contained to the area that it occurred.

\section{Kitchen Fires}

Kitchen fires are another large cause of fires in all facilities with kitchens. As seen in the figure below, cooking equipment makes up $65 \%$ of all health care facility fires.

The studied facility has an R-102 Ansul System which consists of a liquid suppression agent that has an activation system that is required to be manually set off with the push of a button.(E, John, 2017) This system is commonly used in many different hospital, restaurant, and hospitality settings. It is tested semi-annually per the Joint Commission requirements which is different than the annual test of the normal fire alarm system. The HVAC system in this area of the facility does not have any direct connection to any patient care areas and if a fire occurred in the kitchen, the patient care areas would not be affected. (C, Donald, 2017)

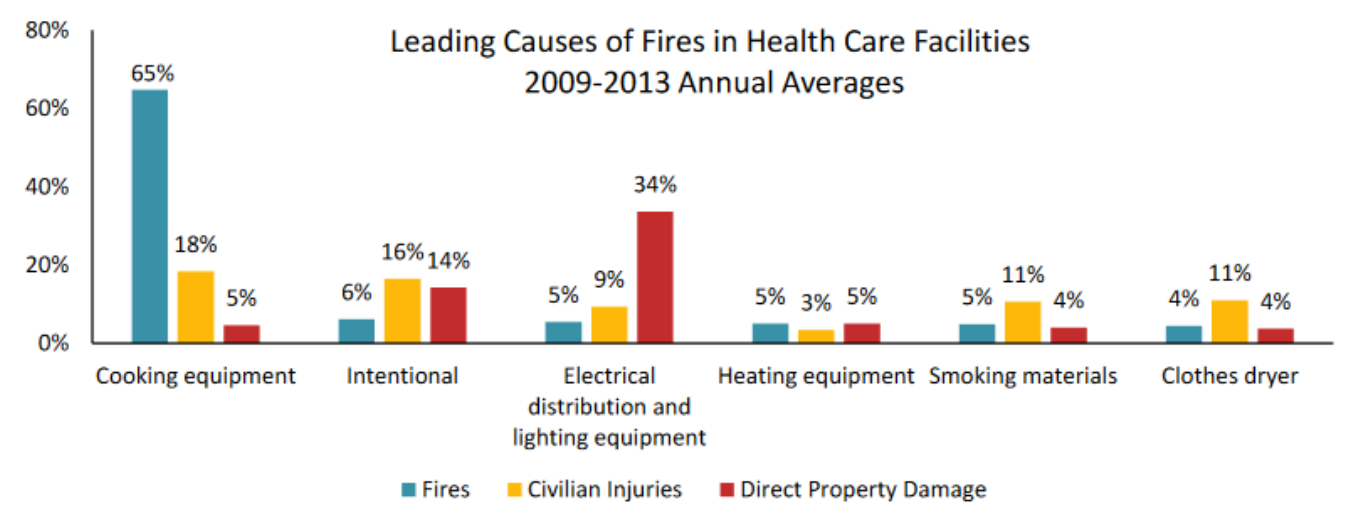

Figure 2 - Leading Cause of Fires in Health Care Facilities (Structure Fires in Health Care Facilities) 
The kitchen HVAC system will only trip into smoke control mode when the sprinklers trip, identical to the rest of the facility. If the Ansul system is fired by a kitchen worker - it will not result in a response from the sprinklers or the HVAC system. Also, the Ansul system is not centrally monitored, meaning that no one will be aware that the system has been set off until a phone call is made to the proper personnel.

\section{Conclusions and Future Research}

The most relevant information on this paper came from the interviewees and ends up being mostly facility specific. Each facility should evaluate its system and determine the need for updating or replacement of pieces of their system to provide the most functional, efficient, and safe system for a facility as critical as a hospital.

The NFPA held a discussion in 2015 and 2016 regarding the possibility of increasing smoke compartment size in hospitals from 22,500 square feet to 40,000 square feet. I brought this to the attention of the interviewees and while it would not specifically impact an existing facility, they had definite thoughts about a change like this.("NFPA 101:

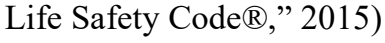

The facility Safety Management staff go through a rigorous checklist for each area of the hospital - detailing each area's need for utilities such as electricity, water, medical oxygen, and many other items. It also details the complexity of moving staff and patients from this area and if the facility has the ability to house these patients at another location in the facility or if they would have to be relocated to an entirely different hospital. (R, Pamela, 2017)

When considering a hospital layout, it is critical to place areas close to each other so the resources are nearby when needed, but also critical to place them far enough apart to make sure that they are not all affected if a single fire event were to occur. If a current facility has adjacent 20,000 SF smoke zones - one being a bank of operating rooms and the other being the intensive care unit that the patients get relocated to after surgery, one of these areas could suffer from a fire event without the other area being affected. If these areas were combined into a single smoke zone - the entire area could be affected in the event of a fire. Obviously, the smoke zones can be made smaller during design of a facility to meet the current need but, in the event of a large remodelling project, this may get overlooked as items like this are not always addressed during the design process. This could cause future problems and a large expense to the facility to break up a large smoke zone into smaller ones.

In addition, the need to upgrade an existing system to a digital system that will report alarms and faults back to a central station is crucial. It is very inefficient for the staff to find a problem with a ward's air pressure only to find that the smoke damper failed and closed. This damper does not report back to a central monitoring station and has to be found solely by manual labor. Since these dampers are required to be tested every 6 years this type of problem is sometimes not always immediately apparent. Some of the other alarm devices are tested annually or semi-annually and are not as big of a problem to replace faulty devices.(R, Pamela, 2017)

An important topic that currently lacks research is that no research has been done to determine the HVAC system capabilities if two (2) zones, being fed by the same HVAC system, catch on fire at roughly the same time. It is unknown if the system can efficiently exhaust that much air to maintain negative pressure without destroying the air handling unit. Today, studies can be done like this with more ease due to 3D building models and the ability to run simulations on with various scenarios to ensure proper function of the system. 


\section{References}

Amin, V. (2014). Integration of Fire Alarm and Automatic Suppression Design in Hospital Renovation Projects - an Overview. Engineered Systems, 31(7), 48-51.

Banse, J. P. (2006). Smoke Control In Health Care Facilities. (cover story). Engineered Systems, 23(8), 31-40.

C, Donald. (2017, July 13). HVAC Shop Foreman Interview.

Dannaway, S. S. (2009). SMOKE DAMPERS Part Of Critical Care. Engineered Systems, 26(7), 20-22.

E, John. (2017, July 9). Emergency Management Tech Interview.

EC.02.05.01 - Clinical Impact | Joint Commission. (n.d.). Retrieved July 9, 2017, from

https://www.jointcommission.org/topics/ec020501_clinical_impact.aspx

Felker, L. (2008). Fire - and Smoke - Damper Control. Heating/Piping/Air Conditioning Engineering, 80(1), 50-54.

Fire Protection - EC.02.03.05 | Joint Commission. (n.d.). Retrieved July 9, 2017, from

http://www.jointcommission.org/topics/fire_protection_ec020305.aspx

Focus on Compliance EC.02.03.05. (n.d.). Retrieved July 9, 2017, from

http://www.ashe.org/compliance/ec_02_05_01/index.shtml

General Requirements - LS.02.01.10 | Joint Commission. (n.d.). Retrieved July 9, 2017, from

http://www.jointcommission.org/topics/general_requirements_ls020110.aspx

Hospital Fires (2012-2014). (n.d.). Retrieved from

https://www.usfa.fema.gov/downloads/pdf/statistics/snapshot_hospital.pdf

Environment of Care Document Checklist.pdf. (2016).

Major Hospital Fires. (n.d.). Retrieved from http://www.nfpa.org/ /media/files/news-and-research/fire-

statistics/occupancies/oshospitalfires.pdf?la=en

NFPA 99: Health Care Facilities Code. (2015).

NFPA 101: Life Safety Code®. (2015).

NFPA Journal - Perspectives, May June 2017. (n.d.). Retrieved July 16, 2017, from http://www.nfpa.org/news-andresearch/publications/nfpa-journal/2017/may-june-2017/pov/perspectives

Ansul Fire Suppression System (n.d.). Retrieved July 16, 2017, from

https://www.ansul.com/en/us/pages/ProductDetail.aspx?productdetail=R-

$102+$ Restaurant+Fire+Suppression+System+

R, Pamela. (2017, July 11). Emergency Manger Interview.

S, Donald. (2017, July 13). HCAV Shop Technician Interview.

Shi, J., Ren, A., \& Chen, C. (2009). Agent-based evacuation model of large public buildings under fire conditions. Automation in Construction, 18(3), 338-347. https://doi.org/10.1016/j.autcon.2008.09.009

Structure Fires in Health Care Facilities. (n.d.). Retrieved from http://www.nfpa.org/ /media/files/news-and-

research/fire-statistics/occupancies/oshealthcarefacilities.pdf?la=en

Top tips for integrating fire protection, HVAC systems | Consulting-Specifying Engineer. (n.d.). Retrieved May 9 , 2017, from http://www.csemag.com/single-article/top-tips-for-integrating-fire-protection-hvac-

systems/44bc49994b8113008940e5e5a639af4f.html

V, Kristian. (2017, July 13). ATS Shop Foreman Interview. 